\title{
Effect of Periodontal Inflammation on Haematological and Liver Function Parameters - A Comparative Clinical Study from Uttar Pradesh, India
}

\author{
Kuldeep Singh ${ }^{1}$, Alka Kanaujia ${ }^{2}$, Savita Singh ${ }^{3}$ \\ 1,3 Department of Pathology, Rama Medical College, Kanpur, Uttar Pradesh, India. \\ 2 Department of Pathology, CHC Hospital, Lakhimpur, Kheri, Uttar Pradesh, India.
}

\section{ABSTRACT}

\section{BACKGROUND}

Periodontitis is an inflammatory disease of periodontium. The inflamed and ulcerated epithelium allows the entry of oral microorganisms, bacterial endotoxins, proinflammatory immune mediators, like Interleukin -1 (IL-1), Interleukin-6 (IL-6), tumour necrosis factor (TNF- $\alpha$ ) and prostaglandin E2 (PGE2) into the systemic circulation, which may produce systemic effects. The present study was conducted to evaluate the effect of periodontal inflammation on haematological and liver function parameters.

\section{METHODS}

The clinical study was conducted among 30 patients with periodontal inflammation. Clinical parameters [plaque index (PI), gingival index (GI), probing pocket depth (PPD)], haematological [RBC count, haemoglobin ( $\mathrm{Hb}$ ) concentration, total leukocyte count and differential leukocyte count] and liver function parameters [alanine aminotransferase (ALT), aspartate aminotransferase (AST) \& alkaline phosphatase (ALP)] were recorded at baseline and after 1 month of scaling and root planning (SRP).

\section{RESULTS}

There was significant improvement in clinical parameters (P-value $<0.001$ ), haematological parameters ( $\mathrm{P}$-value $<0.001)$, except eosinophils $(\mathrm{P}=0.303)$ and basophils $(\mathrm{P}=0.860)$. Changes in liver function test $(\mathrm{LFT})$ parameters were found to be significant $(\mathrm{P}<0.05)$ after SRP.

\section{CONCLUSIONS}

There is an association between periodontal inflammation and systemic parameters.
Corresponding Author:

Dr. Kuldeep Singh,

\#117/245 G, O Block, Geeta Nagar,

Kanpur, Uttar Pradesh, India.

E-mail:dr.kuldeep121@gmail.com

DOI: $10.14260 / j e m d s / 2021 / 282$

How to Cite This Article:

Singh K, Kanaujia A, Singh S. Effect of periodontal inflammation on haematological and liver function parameters - a comparative clinical study from Uttar Pradesh, India. J Evolution Med Dent Sci 2021;10(18):1338-1342, DOI: 10.14260/jemds/2021/282

Submission 13-12-2020,

Peer Review 06-03-2021,

Acceptance 12-03-2021,

Published 03-05-2021.

Copyright (C) 2021 Kuldeep Singh et al. This is an open access article distributed under Creative Commons Attribution License [Attribution 4.0 International (CC BY 4.0)]

\section{KEY WORDS}

Periodontal Inflammation, Haematological, LFT. 


\section{BACKGROUND}

An association between oral infections and systemic diseases has been suspected for centuries. Over the past decade, scientific evidence suggests an association between oral infection and systemic diseases such as atherosclerosis, cardiovascular diseases (CVDs), cerebrovascular disease, premature and low birth weight and pulmonary diseases. It is because the microbes associated with the periodontal disease process invoke an inflammatory response which leads to release of various cytokines. These cytokines and other inflammatory mediators reach to the distant sites via the vascular circulation and play a key role in the pathogenesis of its systemic effects. ${ }^{1}$

The adult human body consists of 1013 somatic cells and 1014 normal or commensal microbes. These commensal bacteria reside on the surfaces of teeth in the form of complex ecosystem termed as biofilm and on the mucosal lining of oral cavity, respiratory tract, oesophagus, gastrointestinal tract and urinary tract. Under some conditions, these microorganisms become opportunistic and are associated with local or systemic infections.

Evidence shows that oral bacteria contribute to systemic diseases. One of the best documented examples is involvement of the gram-positive Streptococcus sanguis and Streptococcus oralis in infective endocarditis. ${ }^{1}$ Leukocytes are an integral part of the innate immune system; these cells are recruited at higher levels during episodes of bacteraemia in periodontitis into the systemic circulation. ${ }^{2}$ The higher number of leukocytes increase the blood rheology, make the blood more viscous and also cells may adhere to the endothelial lining of the blood vessels causing decrease in the blood flow. Reduced blood flow could play a role in relation to CVDs, especially in narrow or partly blocked arteries. So, the blood count can give a definite hint about underlying disease. . $^{3,4}$

The systemic effects of periodontal diseases are known to be caused by bacteraemia arising from diseased periodontal tissues and the resultant inflammatory response. This inflammatory response can lead to changes in commonly assessed blood parameters i.e. RBC count, haemoglobin concentration, total leukocyte count, differential leukocyte count and liver function test parameters. $5,6,7,8$

Periodontitis is an inflammatory disease of periodontium that contributes to an increase in cytokines including tumour necrosis factor- $\alpha$ (TNF- $\alpha$ ), interleukin- 6 (IL- 6) and highsensitivity C-reactive protein (hs-CRP). These cytokines defend the body against infection. However, they can also affect normal body functions such as it may interfere with production and normal activity of erythropoietin and iron absorption resulting in decreased RBC count and haemoglobin concentration.

Inflammatory reaction affects erythrocyte sedimentation rate by increasing concentrations of fibrinogen and alpha globulins. Increase in white blood cell (WBC) count is known as leukocytosis and is a frequent sign of an inflammatory response. ${ }^{9,10}$

Aspartate Aminotransferase is a soluble cytosolic enzyme which is restricted to the cell cytoplasm. It is released into extracellular fluid upon cell death. Similarly, Alanine Aminotransferase is also associated with cell injury and cell death.
Since cell death is an integral and critical component of periodontal tissue destruction, AST and ALT should be released during this process. So, increased level of AST and ALT in serum can be a useful marker of periodontal disease activity. $8,11,12,13$

Alkaline phosphatase is a membrane-bound glycoprotein produced by many cells, such as polymorphonuclear leukocytes, osteoblasts, macrophages and fibroblasts. It is present in many tissues, including bone, intestine, kidney, liver and placenta. Pathologic changes to these tissues cause the release of ALP into the systemic circulation.

Elevated ALP is most commonly caused by liver disease and bone disorders. As there is alveolar bone loss in periodontitis, it may cause elevated serum ALP level. It is released from neutrophils, osteoblasts and periodontal fibroblasts during inflammation, bone formation and periodontal regeneration respectively. Thus, it has dual involvement in the process of periodontal inflammation and healing / regeneration.

ALP allows bone mineralization by releasing an organic phosphate that contributes to the deposition of calcium phosphate complexes into the osteoid matrix. It also promotes mineralization by hydrolysing inorganic pyrophosphate, a potent inhibitor of hydroxy apatite crystal formation and dissolution, within the extracellular calcifying matrix vesicles. ${ }^{14,15,16,17}$

The present study was conducted to evaluate the effect of periodontal inflammation on haematological and liver function parameters.

\section{METHODS}

The present clinical study was carried out among 30 systemically healthy patients aged between 18 to 60 years selected from Outpatient Department of Periodontology, Uttar Pradesh University of Medical Sciences Saifai, Etawah, U.P. India. Sample size was taken based on the convenience of the study.

Study was conducted from January 2018 to June 2019. The research protocol was submitted to the institutional ethical committee \& review board and ethical approval obtained.

All patients were verbally informed about the study protocol and a written informed consent was obtained. Patients were selected on the basis of following criteria.

\section{Inclusion Criteria}

- $\quad$ Presence of at least 20 teeth

- $\quad$ Probing pocket depth (PPD) $\leq 5 \mathrm{~mm}$ at least $30 \%$ sites

- $\quad$ Gingival index $(\mathrm{GI}) \approx 2$

\section{Exclusion Criteria}

- Individuals suffering from any systemic disease.

- History of periodontal treatment or use of any drug for at least 3 months prior to the study.

- Individuals with history of malaria or jaundice in the last 1 year.

- Smokers, tobacco chewers and alcohol abuse.

- $\quad$ Pregnant and lactating female. 


\section{Study Parameters}

All the selected patients were evaluated for the following parameters

\section{Clinical Parameters}

Periodontal status of patients included in the study was recorded using following periodontal parameters.

- Plaque index - Is measuring of dental plaque in area adjacent to gingival margin.

- Gingival index

- Probing pocket depth using UNC-15 probe \{Hu Friedy\}, the probe is placed onto the tooth and the distance between cement-enamel junction and the gingival margin is measured.

\section{Haematological Parameters}

- $\quad$ Red blood cell (RBC) count

- Haemoglobin concentration

- Total leukocyte count

- Differential leukocyte count

\section{Liver Function Test Parameters}

- Alanine aminotransferase

- Aspartate aminotransferase

- Alkaline phosphatases

\section{Statistical Analysis}

The results were analysed using descriptive statistics and making comparisons among the various groups. Discrete (categorical) data was summarized as in proportions and percentages (\%). The normality of data is tested by Kolmogorov test and according to data, nature parametric or non-parametric tests were applied. The following statistics were calculated in the present analysis. The test applied

1. Arithmetic Mean

2. Standard deviation $(\sigma)$

3. Paired t test

4. Wilcoxon signed rank test

\section{Statistical Significance}

In testing a given hypothesis, the maximum probability with which we would be willing to take risk is called level of significance of the test.

- P-value $\geq 0.05$ - Non-significant

- $\quad$ P-value $<0.05$ - Significant

- P-value $<0.01$ - Highly Significant

\section{RESULTS}

The present study was done to assess the effect of periodontal inflammation on haematological and liver function parameters. A total of 30 patients were included in the study fulfilling the inclusion criteria.

Observations for the clinical parameters i.e. PI, GI, PPD, haematological parameters i.e. RBC count, Hb conc., TLC, DLC and liver function parameters i.e. AST, ALT and ALP were made at baseline and after 1 month of SRP.

\begin{tabular}{|ccc|}
\hline Age (in Years) & No. of Patients & Percentage (\%) \\
$18-24$ & 11 & 36.7 \\
$25-34$ & 11 & 36.7 \\
$35-44$ & 5 & 16.7 \\
$45-60$ & 3 & 10.0 \\
Total & $\mathbf{3 0}$ & $\mathbf{1 0 0 . 0}$ \\
Mean \pm SD & \multicolumn{2}{|c|}{$29.27 \pm 10.39$} \\
\hline \multicolumn{2}{|c|}{ Table 1. Age Wise Distribution of Patients } \\
\hline
\end{tabular}

\begin{tabular}{|c|c|c|c|c|c|c|c|}
\hline \multicolumn{2}{|c|}{ Clinical Parameters } & \multirow{2}{*}{$\begin{array}{c}\text { Mean } \\
2.17\end{array}$} & \multirow{2}{*}{$\begin{array}{l}\text { SD } \\
0.37\end{array}$} & \multirow{2}{*}{$\begin{array}{c}\text { Mean } \\
\text { Diff. } \\
1.60\end{array}$} & \multirow{3}{*}{ 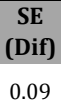 } & \multirow{3}{*}{$\begin{array}{c}\begin{array}{c}\text { t- } \\
\text { Value }\end{array} \\
17.97\end{array}$} & \multirow{3}{*}{$\begin{array}{c}\text { P- } \\
\text { Value } \\
< \\
0\end{array}$} \\
\hline \multirow{2}{*}{ Plaque Index } & Baseline & & & & & & \\
\hline & 1 month & 0.57 & 0.23 & 1.60 & & & \\
\hline \multirow[t]{2}{*}{ Gingival index } & Baseline & 2.03 & 0.31 & \multirow{2}{*}{1.48} & \multirow{2}{*}{0.07} & \multirow{2}{*}{20.83} & $<$ \\
\hline & 1 month & 0.55 & 0.22 & & & & 0.001 \\
\hline \multirow{2}{*}{$\begin{array}{c}\text { Probing pocket } \\
\text { depth }\end{array}$} & Baseline & 3.86 & 0.45 & \multirow{2}{*}{0.92} & \multirow{2}{*}{0.08} & \multirow{2}{*}{12.08} & $<$ \\
\hline & 1 month & 2.94 & 0.37 & & & & 0.001 \\
\hline \multicolumn{8}{|c|}{$\begin{array}{l}\text { Table 2. Assessment of Plaque Index / Gingival Index / Probing Pocket } \\
\text { Depth, at Baseline and after } 1 \text { Month of Scaling and Root Planing }\end{array}$} \\
\hline \multicolumn{8}{|l|}{ Paired $\mathrm{t}$ - test } \\
\hline
\end{tabular}

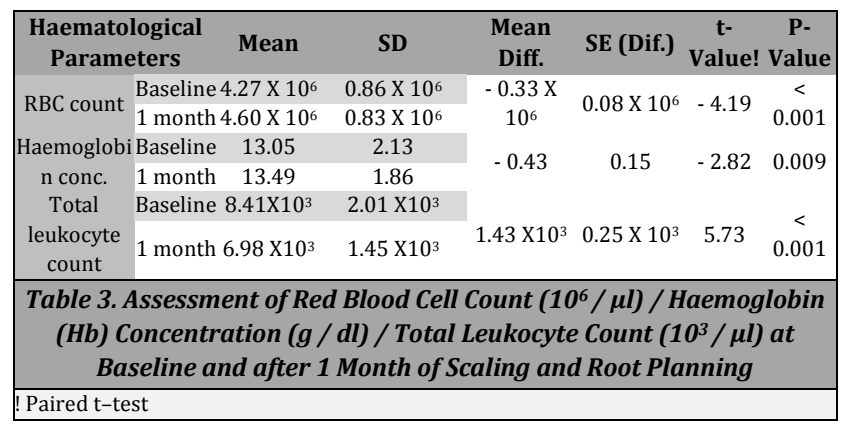

\begin{tabular}{|c|c|c|c|c|c|c|c|}
\hline \multicolumn{2}{|c|}{$\begin{array}{l}\text { Liver Function } \\
\text { Parameters }\end{array}$} & \multirow{2}{*}{$\begin{array}{c}\text { Mean } \\
36.27\end{array}$} & \multirow{2}{*}{$\begin{array}{c}\text { SD } \\
17.11\end{array}$} & \multirow{3}{*}{$\begin{array}{c}\text { Mean } \\
\text { Diff } \\
2.87\end{array}$} & \multirow{3}{*}{$\begin{array}{c}\begin{array}{c}\text { SE } \\
\text { (Diff) }\end{array} \\
1.69\end{array}$} & \multirow{3}{*}{ 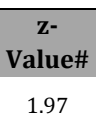 } & \multirow{3}{*}{$\begin{array}{c}\begin{array}{c}\text { P- } \\
\text { Value }\end{array} \\
0.049\end{array}$} \\
\hline Alanine & Baseline & & & & & & \\
\hline Aminotransferase & 1 month & 33.40 & 17.58 & & & & \\
\hline Aspartate & Baseline & 31.13 & 8.69 & \multirow{2}{*}{2.90} & \multirow{2}{*}{1.39} & \multirow{2}{*}{2.09} & \multirow{2}{*}{0.046} \\
\hline Aminotransferase & 1 month & 28.23 & 7.48 & & & & \\
\hline Alkaline & Baseline & 185.67 & 53.98 & \multirow{2}{*}{24.33} & \multirow{2}{*}{11.81} & \multirow{2}{*}{2.06} & \multirow{2}{*}{0.048} \\
\hline Phosphatase & 1 month & 161.33 & 64.34 & & & & \\
\hline $\begin{array}{r}\text { Table 4. A } \\
\text { osphatase a }\end{array}$ & $m a n+2 x+10$ & $4 a_{1}$ & $A n$ & 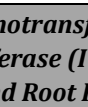 & 1 & $\overline{y l k}$ & $e$ \\
\hline
\end{tabular}

\begin{tabular}{|c|c|c|c|c|c|c|c|}
\hline \multicolumn{2}{|c|}{ Differential Leukocyte Count } & Mean & SD & Mean Diff. & SE (Dif.) & z-Value\# & P-Value \\
\hline \multirow{2}{*}{ Neutrophil count } & Baseline & $5.20 \times 10^{3}$ & $1.38 \times 10^{3}$ & \multirow{2}{*}{$0.76 \times 10^{3}$} & \multirow{2}{*}{$0.20 \times 10^{3}$} & \multirow{2}{*}{3.09} & \multirow{2}{*}{0.002} \\
\hline & 1 month & $4.44 \times 10^{3}$ & $0.86 \times 10^{3}$ & & & & \\
\hline \multirow{2}{*}{ Lymphocyte count } & Baseline & $2.44 \times 10^{3}$ & $0.80 \times 10^{3}$ & \multirow{2}{*}{$0.39 \times 10^{3}$} & \multirow{2}{*}{$0.09 \times 10^{3}$} & \multirow{2}{*}{3.96} & \multirow[b]{2}{*}{$<0.001$} \\
\hline & 1 month & $2.05 \times 10^{3}$ & $0.54 \times 10^{3}$ & & & & \\
\hline \multirow{2}{*}{ Monocyte count } & Baseline & $0.40 \times 10^{3}$ & $0.56 \times 10^{3}$ & \multirow{2}{*}{$0.17 \times 10^{3}$} & \multirow{2}{*}{$0.10 \times 10^{3}$} & \multirow{2}{*}{4.02} & \multirow{2}{*}{$<0.001$} \\
\hline & 1 month & $0.22 \times 10^{3}$ & $0.08 \times 10^{3}$ & & & & \\
\hline \multirow{2}{*}{ Eosinophil count } & Baseline & $0.62 \times 10^{3}$ & $1.08 \times 10^{3}$ & \multirow{2}{*}{$0.26 \times 10^{3}$} & \multirow{2}{*}{$0.15 \times 10^{3}$} & \multirow{2}{*}{1.03} & \multirow{2}{*}{0.303} \\
\hline & 1 month & $0.35 \times 10^{3}$ & $0.31 \times 10^{3}$ & & & & \\
\hline \multirow{2}{*}{ Basophil count } & Baseline & $0.032 \times 10^{3}$ & $0.03 \times 10^{3}$ & \multirow{2}{*}{$-0.003 \times 10^{3}$} & \multirow{2}{*}{$0.01 \times 10^{3}$} & \multirow{2}{*}{-0.18} & \multirow{2}{*}{0.860} \\
\hline & 1 month & $0.035 \times 10^{3}$ & $0.04 \times 10^{3}$ & & & & \\
\hline
\end{tabular}




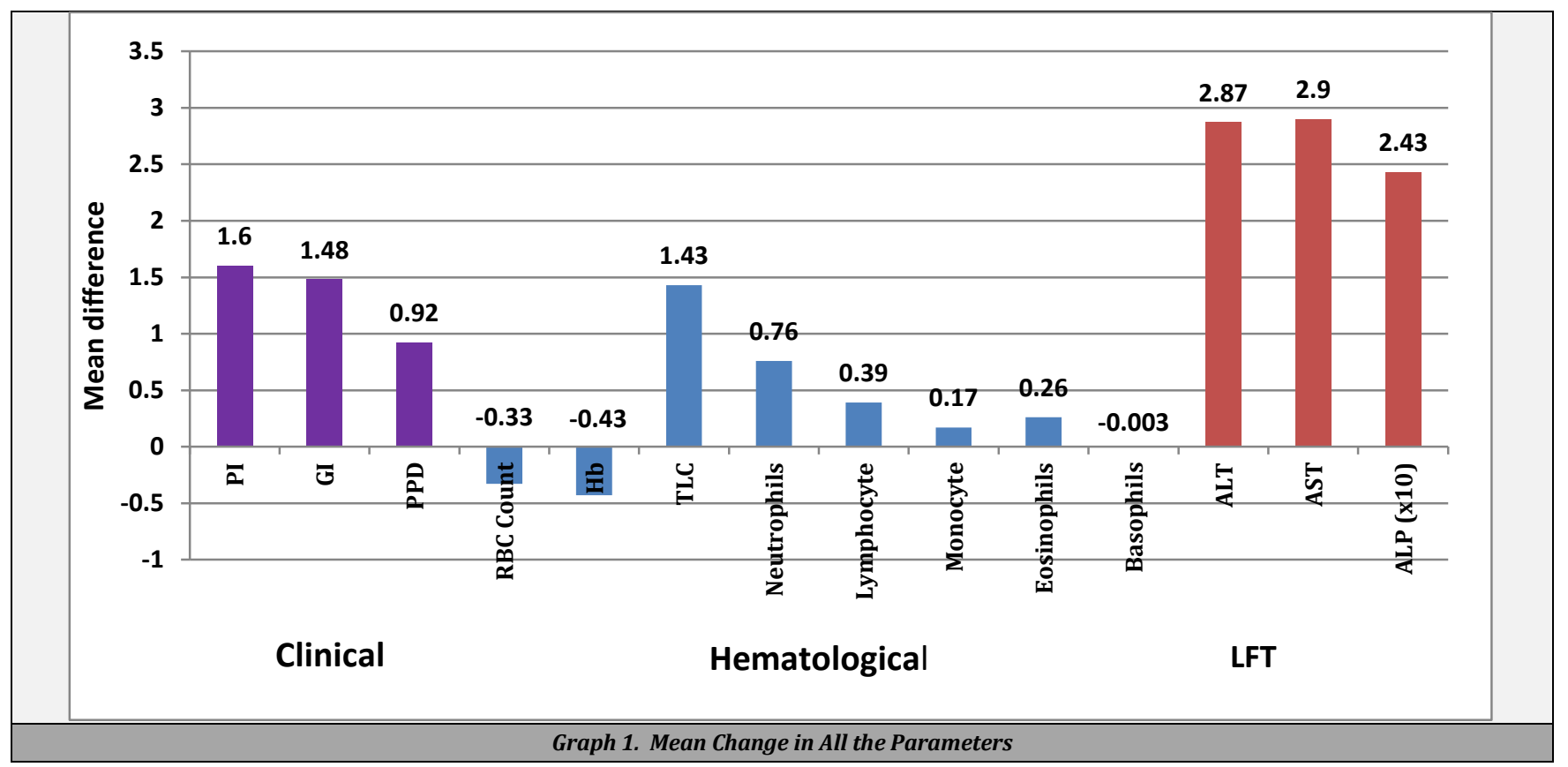

After scaling and root planning, changes in the clinical parameters and haematological parameters were found to be highly significant $(\mathrm{P}<0.01)$ except eosinophils $(\mathrm{P}=0.303)$ and basophils $(\mathrm{P}=0.860)$. Changes in LFT parameters were found to be significant $(\mathrm{P}<0.05)$ after SRP (Table 6 \& Graph 1$)$

\begin{tabular}{|c|c|c|c|c|c|}
\hline Type & Parameter & Mean Diff. & SE (Dif.) & P-Value & Significance \\
\hline \multirow{4}{*}{ Clinical } & PI & 1.60 & 0.09 & $<0.001$ & HS \\
\hline & GI & 1.48 & 0.07 & $<0.001$ & HS \\
\hline & PPD & 0.92 & 0.08 & $<0.001$ & HS \\
\hline & RBC Count & $-0.33 \times 10^{6}$ & $0.08 \times 10^{6}$ & $<0.001$ & HS \\
\hline \multirow{7}{*}{ Haematological } & $\mathrm{Hb}$ & -0.43 & 0.15 & 0.009 & HS \\
\hline & TLC & $1.43 \times 10^{3}$ & $0.25 \times 10^{3}$ & $<0.001$ & HS \\
\hline & Neutrophils & $0.76 \times 10^{3}$ & $0.20 \times 10^{3}$ & 0.002 & HS \\
\hline & Lymphocyte & $0.39 \times 10^{3}$ & $0.09 \times 10^{3}$ & $<0.001$ & HS \\
\hline & Monocyte & $0.17 \times 10^{3}$ & $0.10 \times 10^{3}$ & $<0.001$ & HS \\
\hline & Eosinophils & $0.26 \times 10^{3}$ & $0.15 \times 10^{3}$ & 0.303 & NS \\
\hline & Basophils & $-0.003 \times 10^{3}$ & $0.01 \times 10^{3}$ & 0.860 & NS \\
\hline \multirow{3}{*}{ LFT } & ALT (IU / L) & 2.87 & 1.69 & 0.049 & $\mathrm{~S}$ \\
\hline & AST (IU / L) & 2.90 & 1.39 & 0.046 & S \\
\hline & $\operatorname{ALP}(\mathrm{IU} / \mathrm{L})$ & 24.33 & 11.81 & 0.048 & $\mathrm{~S}$ \\
\hline
\end{tabular}

\section{DISCUSSION}

The present study was carried out to evaluate the effect of periodontal inflammation on haematological and liver function parameters. All clinical periodontal examinations were performed by single examiner to minimize the interexaminer variations. To assess the effect of SRP, the changes in the periodontal parameters were evaluated at baseline and 30 days after SRP. A statistically highly significant reduction were found in mean value of PI $(2.17 \pm 0.37$ at baseline, $0.57 \pm 0.23$ after 1 month), GI (2.03 \pm 0.31 at baseline $0.55 \pm 0.22$ after 1 month) and PPD (3.86 $\pm 0.45 \mathrm{~mm}$ at baseline, $2.94 \pm 0.37 \mathrm{~mm}$ after 1 month) suggesting that SRP and motivation for oral hygiene measures helped in improving the periodontal health thus reducing the periodontal inflammation of patients. The similar findings were also observed by Patel MD et al. ${ }^{18}$ in their study.
Periodontal inflammation may affect haematological parameters via the release of various cytokines into the systemic circulation. In present study, mean value of RBC count and haemoglobin concentration were $4.27 \times 10^{6} \pm 0.86$ $\mathrm{X} 10^{6} / \mu \mathrm{l}$ and $13.05 \pm 2.13 \mathrm{~g} / \mathrm{dl}$ respectively at baseline and the level improves to $4.60 \times 10^{6} \pm 0.83 \times 10^{6} / \mu \mathrm{l}$ and $13.49 \pm$ $1.86 \mathrm{~g} / \mathrm{dl}$ after resolution of periodontal inflammation and these mean increases were found to be highly significant. These findings of present study were in favour of research work carried out by Agarwal $\mathrm{N}$ et al. ${ }^{19}$

Seigel $\mathrm{EH}^{20}$ had reported a depression in the number of erythrocytes in presence of periodontal disease and their elevation after the pathological process arrest. Thomas B et al. ${ }^{21}$ showed that periodontitis patient has a lower haematocrit, lower number of erythrocytes, lower haemoglobin levels and higher erythrocyte sedimentation rates. Whereas, the studies by Wakai K et al. ${ }^{22}$ and HavemosePoulsen A et al. ${ }^{23}$ failed to show any association between haemoglobin level and periodontal status.

In present study the mean values of ALT \& AST level at baseline were $36.27 \pm 17.11 \mathrm{IU} / \mathrm{L} \& 31.13 \pm 8.69 \mathrm{IU} / \mathrm{L}$ respectively which reduced to $33.40 \pm 17.58 \mathrm{IU} / \mathrm{L} \& 28.23 \pm$ $7.48 \mathrm{IU} / \mathrm{L}$ respectively after 1 month of scaling and root planing. The mean reduction in ALT \& AST after scaling and root planing were $2.87 \pm 1.69 \mathrm{IU} / \mathrm{L} \& 2.90 \pm 1.39 \mathrm{IU} / \mathrm{L}$ respectively. These reductions were statistically significant. This reflects that the AST \& ALT release is associated with periodontal inflammation. Khatavkar PR et al. ${ }^{8}$ in their study found that AST \& ALT levels were reduced significantly after treatment suggesting that AST and ALT level decreases when periodontal status improves is in accordance with present study. The relationship of ALT \& AST level with periodontal tissue destruction was also observed locally in gingival crevicular field (GCF). Shimada K et al. ${ }^{24}$ suggested that AST level in GCF decreases when periodontal status improves. Arora $\mathrm{VK}^{25}$ analysed the level of AST in GCF in patients with chronic periodontitis and observed the reduction in AST level with the improvement in clinical parameters after nonsurgical periodontal therapy. According to Kuroki A et al. ${ }^{26}$ 


\section{CONCLUSIONS}

The result of present study shows a correlation between periodontal inflammation and haematological \& liver function parameters. The levels of haematological parameters; RBC count, $\mathrm{Hb}$ concentration were increased and TLC \& DLC decreased without significant change in the eosinophil \& basophil count. The liver function parameters (ALT, AST \& ALP) reduced once the periodontal inflammation resolved. This reflects that the levels of serum enzymes ALT, AST \& ALP are related to periodontal inflammation. Thus, periodontal inflammation has systemic effects as the chemical mediators involved in inflammation are same for any systemic inflammatory disease. However, further longitudinal clinical studies with larger sample size are needed to validate the association among the periodontal inflammation and systemic parameters.

Data sharing statement provided by the authors is available with the full text of this article at jemds.com.

Financial or other competing interests: None.

Disclosure forms provided by the authors are available with the full text of this article at jemds.com.

\section{REFERENCES}

[1] Cohen DW, Slavkin HC. Periodontal Medicine. In: Rose LF, Genco RJ, Mealey BL, et al. eds. Periodontal disease and systemic disease. London: B.C. Decker Inc., 2000: p. 1-10.

[2] Loos BG. Systemic markers of inflammation in periodontitis. J Periodontol 2005;76(11 Suppl):2106-15.

[3] Kannel WB, Anderson K, Wilson PW. White blood cell count and cardiovascular disease. Insights from the framingham study. JAMA 1992;267(9):1253-6.

[4] Sweetnam PM, Thomas HF, Yarnell JW, et al. Total and differential leukocyte counts as predictors of ischemic heart disease: the caerphilly and speedwell studies. Am J Epidemiol 1997;145(5):416-21.

[5] Kalsi DS, Sood A, Mundi S, et al. Effect of scaling and root planing on blood counts in patients with chronic generalized periodontitis. Indian J Dent Sci 2017;9(2):109-13.

[6] Perumal GCL, Mythili R, Kumar S, et al. Serum total alkaline phosphatase enzyme level and severity of chronic periodontitis. Int J Cur Res Rev 2014;6(17):41-4.

[7] Soud P, Gupta HL, Kumar P, et al. Estimation and comparison of levels of Alkaline Phosphatase (ALP), Acid Phosphatase (ACP), Calcium (Ca) and Potassium (K) in serum of subjects with and without Periodontal Disease (PD). International Journal of Applied Dental Sciences 2015;1(4):90-3.

[8] Khatavkar PR, Patil RA, Gurav AN, et al. Effect of scaling and root planing on liver function test (Alanine Aminotransferase and Aspartate Aminotransferase) in systemically healthy-chronic periodontitis subjects: a clinical trial. Sch J Dent Sci 2016;3(10):290-5.

[9] Nemeth E, Ganz T. Anemia of inflammation. Hematol Oncol Clin North Am 2014;28(4):671-81.

[10] Harrison M. Erythrocyte sedimentation rate and Creactive protein. Aust Prescr 2015;38(3):93-4.
[11] Persson GR, Page RC. Diagnostic characteristics of crevicular fluid aspartate aminotransferase (AST) levels associated with periodontal disease activity. J Clin Periodontol 1992;19(1):43-8.

[12] Adolph L, Lorenz R. Enzyme diagnosis in diseases of the heart, liver and pancreas. Basel, Karger 1982: p. 64-80.

[13] Furuta M, Ekuni D, Yamamoto T, et al. Relationship between periodontitis and hepatic abnormalities in young adults. Acta Odontol Scand 2010;68(1):27-33.

[14] Perinetti G, Paolantonio M, Femminella B, et al. Gingival crevicular fluid alkaline phosphatase activity reflects periodontal healing/recurrent inflammation phases in chronic periodontitis patients. J Periodontol 2008;79(7):1200-7.

[15] Daltaban O, Saygun I, Bal B, et al. Gingival crevicular fluid alkaline phosphatase levels in postmenopausal women: effects of phase I periodontal treatment. J Periodontol 2006;77(1):67-72.

[16] Taylor K, Lueken SA, Libanati C, et al. Biochemical markers of bone turnover for the clinical assessment of bone metabolism. Rheum Dis Clin N Am 1994;20(3):589607.

[17] Garnero P, Delmas PD. Biochemical markers of bone turnover. Endocrinol Metab Clin North Am 1998;27(2):303-23.

[18] Patel MD, Shakir QJ, Shetty A. Interrelationship between chronic periodontitis and anemia: a 6-month follow-up study. J Indian Soc Periodontol 2014;18(1):19-25.

[19] Agarwal N, Kumar VSC, Gujjari SA. Effect of periodontal therapy on hemoglobin and erythrocyte levels in chronic generalized periodontitis patients: an interventional study. J Indian Soc Periodontol 2009;13(1):6-11.

[20] Seigel EH. Total erythrocyte, leucocyte and differential white cell counts of blood in chronic periodontal disease. J Dent Res 1945;24:270.

[21] Thomas B, Ramesh A, Ritesh K. Relationship between periodontitis and erythrocyte count. J Indian Soc Periodontol 2006;10(2):288-91.

[22] Wakai K, Kawamura T, Umemura O, et al. Associations of medical status and physical fitness with periodontal disease. J Clin Periodontol 1999;26(10):664-72.

[23] Havemose-Poulsen A, Westergaard J, Stoltze K, et al. Periodontal and hematological characteristics associated with aggressive periodontitis, juvenile idiopathic arthritis and rheumatoid arthritis. J Periodontol 2006;77(2):2808.

[24] Shimada K, Mizuno T, Ohshio K, et al. Analysis of aspartate aminotransferase in gingival crevicular fluid assessed by using pocket watch: a longitudinal study with initial therapy. J Clin Periodontol 2000;27(11):819-23.

[25] Arora VK, Chaubey KK, Gupta S, et al. Effect of nonsurgical therapy on GCF aspartate aminotransferase levels in chronic periodontitis patients. Indian Journal of Dental Sciences 2010;2(2):40-6.

[26] Kuroki AA, Sugita N, Komatsu S, et al. Association of liver enzyme levels and alveolar bone loss: a cross-sectional clinical study in Sado Island. J Clin Exp Dent 2018;10(2):100-6 